\title{
Birth preparedness and complication readiness among pregnant women in Tehulederie district, Northeast Ethiopia: a community-based cross-sectional study
}

Demlie Belete Endeshaw ${ }^{1}$, Lema Derseh Gezie ${ }^{2}$ and Hedija Yenus Yeshita ${ }^{3^{*}}$

\begin{abstract}
Background: Motherhood is a time of anticipation of joy for a woman, her family, and her community. In spite of this fact, it is not as enjoyable as it should be because of numerous reasons. Insufficiency or lack of birth preparedness and complication readiness is the most common reason. The aim of this study was to assess the practice of birth preparedness and complication readiness and associated factors among pregnant women in Tehuledere district, northeast Ethiopia.
\end{abstract}

Methods: A community-based cross-sectional study was conducted in Tehuledere district, northeast Ethiopia. Participants were selected using the multistage sampling technique, and data were analyzed both descriptively and analytically using the binary logistic regression.

Result: Out of the total 507 samples, 500 (response rate 98.6\%) pregnant women participated in the study. Less than half (44.6\%) and (43.4\%) of the respondents had knowledge and practice on birth preparedness and complication readiness, respectively. In the multivariate analysis, knowledge of birth preparedness and complication readiness ( $\mathrm{AOR}=1.648$, 95\%Cl: 1.073, 2.531), knowledge of danger signs during pregnancy ( $\mathrm{AOR}=2.802,95 \% \mathrm{Cl}: 1.637,4.793)$, gestational age $(A O R=3.379,95 \% \mathrm{Cl}: 2.114,5.401)$, and antenatal care follow up starting time (AOR $=2.841,95 \% \mathrm{Cl}: 1.330,6.068)$ were significantly associated with the practice of birth preparedness and complication readiness, but pregnant women in rural areas (AOR $=0.442,95 \% \mathrm{Cl}: 0.244,0.803$ ) were less associated with birth preparedness and complication readiness compared to women in urban settlements.

Conclusion: This study identified that poor knowledge, inadequate birth preparedness, and complication readiness were prevalent among mothers in the study area. Government officials, partners, and health care providers working in the areas of maternal and child health should operate together to maximize birth preparedness and complication readiness practices.

Keywords: Birth preparedness, Complication readiness, Knowledge, Danger signs, Northeast Ethiopia

\footnotetext{
* Correspondence: kedijayenus@gmail.com

${ }^{3}$ Department of Reproductive Health, Institute of Public health, University of

Gondar, Gondar, Ethiopia

Full list of author information is available at the end of the article
} 


\section{Background}

Motherhood is a time of expectation and joy for a woman, her family, and her community. However, for thousands of women, the experience is not as pleasurable an event as it should be [1].

Each year in Africa 30 million women become pregnant, and about 250,000 of them die from pregnancy-related causes [2]. It is not possible to predict which women will experience life-threatening obstetric complications that lead to maternal mortality. On the whole, $42 \%$ of all pregnancies suffer complications - in rich and poor countries alike - and in $15 \%$ of all pregnancies, the complications are life-threatening. Scaling up birth preparedness and complication readiness (BPCR) practices and providing care by skilled providers (doctor', nurse' or midwives) during pregnancy, childbirth, and in the immediate postnatal period are fundamental for maternal health [2].

In many societies in the world, cultural beliefs and lack of knowledge of BPCR inhibit in advance preparations for delivery and expected babies. Since no action is taken prior to delivery, the family tries to act only when labor begins. To this end, the utilization of BPCR is the cornerstone for most developing countries, including Ethiopia. It is a strategy to promote a timely use of skilled maternal and neonatal care, especially during pregnancy, childbirth, and through the two-day post-partum period. The role of BPCR is to improve the use and effectiveness of key maternal and neonatal services through reducing the deadly delays (the first two delays) in deciding to seek care. Due to increases in the level of knowledge about complication readiness and the recognition of danger signs, the identification of problems and the delays in seeking health care services have been improved [3-8].

The Ministry of Health $(\mathrm{MOH})$ has designed \& initiated the application of BPCR in different maternal and neonatal health interventions to reduce maternal and newborn morbidity and mortality in Ethiopia. Currently, the Maternal Mortality Rate (MMR) of Ethiopia is 420 per 100,000 live births. Only $15 \%$ of the births in Ethiopia are at health facilities, $14 \%$ at public and $1 \%$ at private $[9,10]$.

Women's BPCR practices were examined by different authors who no doubt used sound methods. For instance, a study conducted in India on BPCR among slum women recognized steps; like identifying a trained birth attendant, selecting a health facility, arranging transport for delivery and obstetric emergency, and saving money for delivery; responding positively to at least three of the four elements was considered as an appropriate preparation [11].

In community-based cross-sectional studies conducted by Mpwapwa district of Tanzania, Plateau district in Nigeria, and a rural district of Ghana on BPCR among women showed that only a few of the women knew three or more obstetric danger signs [12-14].
According to a study conducted in rural Uganda, 52\% of women knew at least one key danger sign during pregnancy, $72 \%$ during delivery and postpartum periods. Overall, 35\% of the respondents who made arrangements in three of the four birth preparedness practices were classified as "well prepared for birth" [15].

A similar study conducted by Ife Central Local Government, Nigeria, on BPCR among pregnant women showed that 158 (39.3\%) respondents knew no danger signs of pregnancy, childbirth, and postpartum periods. Only $24(6.0 \%)$ had adequate knowledge of obstetric danger signs without prompting. Three hundred and forty $(84.8 \%)$ of women identified birthplaces and 312 (78.3\%) began saving money for delivery. However, 304 (79.4\%) of the women made no arrangements for blood donors [16]. Other studies conducted in Adigrat and Goba districts of Ethiopia showed that only 118 (22.1\%) and 128 (29.9\%) of the total respondents, respectively, were found to be well prepared ahead of childbirth $[17,18]$.

A study done in Aleta Wondo district using five measures of BPCR that included identifying health provider, health facility and potential blood donor, the arrangement of transportation, and saving money for costs of delivery and emergency showed that among 743 pregnant women, only $20.5 \%$ identified skilled providers. In the same study, only $8.1 \%$ identified health facilities for delivery and/or for obstetric emergencies. On the other hand, the majority $(87.9 \%)$ of the respondents reported that they intended to deliver at home, whereas only $60(8 \%)$ planned to deliver at health facilities, and $17 \%$ of the pregnant women were well prepared [19].

A study on the elements of BPCR in Jimma, Ethiopia, reported that $12.5 \%, 65.7 \%, 81 \%, 20.2 \%$, and $58.9 \%$ of the pregnant women made prior decisions regarding skilled birth attendance, money, place of delivery, mode of transportation, and potential blood donor, respectively. On the whole, the study identified that less than onethird, 106 (29.4\%) of the study participants were prepared for BPCR, indicating the prevalence or existence of poor practices or preparedness for birth and its complications in the area [20].

With regard to risk factors, studies done in Adigrate and Goba districts showed that residence, occupation, educational level, family size, ANC follow up, knowledge of danger signs during pregnancy, labor and postnatal period, as well as gravida and parity were found to have statistically significant associations with $\operatorname{BPCR}[17,18]$.

Generally, almost all of the findings in the above studies revealed that $\mathrm{BPCR}$ remains almost unutilized to improve maternal and neonatal health in most developing countries, especially in sub-Saharan Africa. Hence, one can clearly understand that among the population studied, BPCR is comparatively low. The findings can also tell us BPCR is very low, especially in Ethiopia, 
compared to findings in other developing countries. As a result, the majority of the pregnant women did not give birth at health institutions; therefore, it is necessary to further investigate knowledge and practice of BPCR and possible associated factors.

As a matter of fact, not only were studies on BPCR in this particular area scarce but also the studies available varied in terms of time and place of study, geographic location, and population. Most previous studies focused on urban communities and among non- pregnant women [17-21]. In addition, the level of BPCR practice and its associated factors among pregnant women was not clearly examined in the study areas. So, the aim of this study was to assess BPCR practices and associated factors among pregnant women in Tehulederie district, Amhara National Regional State, northeast Ethiopia. Hence, the findings of the study will be crucial for the study woreda health officials, South Wollo zone health departments, the Amhara National Regional Health Bureau, and other maternal and neonatal health program implementers.

\section{Methods}

\section{Study design and setting}

A community-based cross-sectional study was conducted in Tehulederie district, the Amhara National Regional State, northeast Ethiopia, 2015. The district had 134,131 inhabitants (48\% female), of which 31,628 were women in the reproductive age group, and 4520 were expectant pregnant women [22]. Tehulederie has a total of 26 kebeles (the lowest administrative units usually with multiple villages). It had 21 health posts, six small private clinics, three medium private clinics, five public health centers, seven drug stores, and one diagnostic facility [23].

The study was intended to represent all pregnant women who had the chance to be sampled in the district. After orientating about the significance of the study, pregnant women able to give informed consent were included.

\section{Sample size determination and sampling procedure}

The required sample size of the study was determined using the single population proportion formula. In determining the sample size, the proportion (p) of BPCR [18], the margin of error or precision (w), and confidence level were assumed to be $29.9 \%, 5 \%$, and $95 \%$, respectively. Moreover, a design effect of 1.5 and a nonresponse rate of $5 \%$ were applied to the initial sample size to get the final one (507).

In the district, about 4520 women were estimated to be eligible, that is expected to be pregnant. First, the district was stratified into urban and rural in order to deal with the effect of residence. Two of the five urban and eight of the twenty-one rural kebeles were proportionately selected by the simple random sampling technique. Then, the total sample size was allocated proportionally to each kebele according to their proportion of pregnant women. Thus, one hundred and seven participants from the two urban kebeles and four hundred from the eight rural kebeles were included in the study. To prepare the frame of pregnant mothers, Health Extension Workers (HEWs) of each selected kebele updated the identifications of pregnant women registered in the health centers/posts. Finally, every third pregnant mother was selected systematically by tracking them with the updated pregnant women registration location.

\section{Operational definitions}

For reasons of clarity and standardization, some concepts were defined operationally. Accordingly, birth preparedness and complication readiness elements included identifying a skilled birth attendant and health facility, arranging means of transport for delivery as well as in case of obstetric emergency, saving money, arranging blood donors in case of obstetric emergency, identifying a birth companion, temporary family caregiver, medical facility in case of obstetric emergency, and decision making in case of emergency.

A woman was considered as "knowledgeable in BPCR" if she identified and mentioned at least six key components of birth preparedness and complication readiness elements [18]. Similarly, a study participant would be considered as "knowledgeable in key danger signs of pregnancy" if she could spontaneously mention at least three key danger signs of pregnancy. On the other hand, a woman would be classified as "knowledgeable in key danger signs of labor" if she could spontaneously mention at least five key danger signs of labor/childbirth. Likewise, a woman would be considered as "knowledgeable in key danger signs of postpartum" if she could spontaneously mention at least five key danger signs of a postpartum period within two days [18].

\section{Data collection procedure}

A close-ended structured questionnaire was used to collect data from the participants. The questionnaire was prepared in English and translated to Amharic and retranslated to English by a language expert to check its consistency (Additional files 1 and 2). The questionnaire included Information on socio-demographic and obstetric characteristics, knowledge questions on key obstetric danger signs, birth preparedness, and complication readiness. After evaluation, the final version of the questionnaire was developed. For each of the questions, a participant who had the practice was given a score of "one", and lack of the practice was given a score of "zero". Seven diploma graduated nurses working out of 
the district, fluent in the local language and familiar with local norms collected the data. The data collectors interviewed participants in person. One BSc. the graduate health officer was assigned to supervise the data collection process. Training was given to both the data collectors and supervisor by the principal investigator for two days.

\section{Data quality control/management}

In order to ensure clarity and consistency, the questionnaire was pretested on $10 \%$ of the sample in a similar population of a nearby kebele. After that, the necessary modifications were made to the items and evidencebased time was allocated to each respondent. All data collected was checked for completeness by the principal investigator and the supervisor immediately at the end of each data collection day.

\section{Data process and analysis}

Data was entered, coded, cleaned and analyzed using SPSS version 20 software. Descriptive statistics such as frequencies and percentages were computed; then, a bivariable analysis was used to examine the crude associations of factors on BPCR. Variables with less than 0.2 $p$-values in the bivariable analysis were candidates for multivariable logistic regressions. Statistical significance was declared at a p-value of 0.05 and adjusted odds ratios were used to determine the strength of associations.

\section{Result}

\section{Socio-demographic characteristics of respondents}

Out of the total 507 samples, only five hundred pregnant women participated in the study, giving a response rate of $98.6 \%$. The mean and \pm Standard Deviation of respondent age was $28.8 \pm 5$ years; women's age ranged from 20 to 38 years. Of the total respondents, 472 (94.4\%) were married and $4.4 \%$ single. Most of the respondents (469 or 93.8\%) were housewives, and 391 (78.2\%) of the pregnant women were rural dwellers; 338 (67.6\%) attended formal school (Table 1).

\section{Obstetric characteristics of respondents}

In the assessment of obstetric characteristics, 135 (27\%) of the respondents were primigravida, and about 365 (73\%) had more than two pregnancies. Regarding gestational age, $185(37 \%)$ respondents were in the first trimester and twenty-five (5\%) in the third trimester. About 358 (71.6\%) respondents had two and more than two ANC visits (Table 2).

Regarding knowledge of key danger signs during pregnancy, childbirth, and the postpartum period within two days, $492(98.4 \%)$ of the 500 respondents reported that they had information about danger signs during
Table 1 Socio-demographic characteristics of pregnant women in Amhara National Regional State, northeast Ethiopia, 2015

\begin{tabular}{|c|c|c|c|}
\hline Variables & Category & Frequency & Percentage \\
\hline \multirow[t]{3}{*}{ Age } & $15-24$ & 107 & 21.4 \\
\hline & $25-34$ & 308 & 61.6 \\
\hline & $35-44$ & 85 & 17.0 \\
\hline \multirow[t]{4}{*}{ Marital status } & Single & 22 & 4.4 \\
\hline & Married & 472 & 94.4 \\
\hline & Divorce & 4 & 0.8 \\
\hline & Widow & 2 & 0.4 \\
\hline \multirow[t]{2}{*}{ Residence } & Urban & 109 & 21.8 \\
\hline & Rural & 391 & 78.2 \\
\hline \multirow[t]{4}{*}{ Occupation } & Housewife & 469 & 93.8 \\
\hline & Government employee & 9 & 1.8 \\
\hline & Merchant & 15 & 3.0 \\
\hline & NGO employee & 7 & 1.4 \\
\hline \multirow[t]{2}{*}{ Religion } & Orthodox & 44 & 8.8 \\
\hline & Muslim & 456 & 91.2 \\
\hline \multirow[t]{3}{*}{ Family size } & $1-3$ & 232 & 46.4 \\
\hline & $4-6$ & 244 & 48.8 \\
\hline & $>/=7$ & 24 & 4.8 \\
\hline \multirow[t]{4}{*}{ Educational status } & No formal education & 338 & 67.6 \\
\hline & Primary education & 98 & 19.6 \\
\hline & Secondary education & 51 & 10.2 \\
\hline & $\begin{array}{l}\text { College and above } \\
\text { college }\end{array}$ & 13 & 2.6 \\
\hline \multirow[t]{3}{*}{ Monthly income } & $<500$ ETB & 226 & 45.2 \\
\hline & 500-1500 ETB & 193 & 38.6 \\
\hline & $>1500$ ETB & 81 & 16.2 \\
\hline Ethnicity & Amhara & 500 & 100.0 \\
\hline \multirow[t]{4}{*}{ Partner education } & No formal education & 343 & 68.6 \\
\hline & Primary education & 59 & 11.8 \\
\hline & Secondary education & 58 & 11.6 \\
\hline & $\begin{array}{l}\text { College and above } \\
\text { College }\end{array}$ & 40 & 8.0 \\
\hline \multirow[t]{4}{*}{ Partner occupation } & Farmer & 354 & 70.8 \\
\hline & Employee & 36 & 7.2 \\
\hline & Merchant & 82 & 16.4 \\
\hline & NGO employee & 28 & 5.6 \\
\hline \multirow{2}{*}{$\begin{array}{l}\text { Distance of HF from } \\
\text { home (round trip) }\end{array}$} & $</=$ one hour & 162 & 33.0 \\
\hline & $>$ one hour & 338 & 67.0 \\
\hline
\end{tabular}

pregnancy, childbirth, and within two days of the postpartum period. About 128 (25.6\%), 333 (66.6\%), and 321 (64.2\%) of the pregnant women were not knowledgeable about danger signs during pregnancy, labor/childbirth and within two days of the postpartum period, respectively. When vaginal bleeding, the most frequently 
Table 2 Obstetric characteristics of pregnant women in Tehulederie district, Amhara National Regional State, northeast Ethiopia, 2015

\begin{tabular}{|c|c|c|c|}
\hline Variables & Category & Frequency & Percentage \\
\hline \multirow[t]{3}{*}{ Gestational age } & $1-3$ months & 185 & 37.0 \\
\hline & 4-6 months & 290 & 58.0 \\
\hline & 7-9 months & 25 & 5.0 \\
\hline \multirow[t]{2}{*}{ Starting time for ANC visit } & No & 4 & .8 \\
\hline & Yes & 496 & 99.2 \\
\hline \multirow[t]{5}{*}{ Number of ANC visits } & One time & 142 & 28.4 \\
\hline & Two times & 168 & 33.6 \\
\hline & Three times & 135 & 27.0 \\
\hline & Four times & 51 & 10.2 \\
\hline & Five times & 4 & .8 \\
\hline \multirow[t]{2}{*}{ ANC service was given by } & $\begin{array}{l}\text { Midwife/clinical } \\
\text { nurse }\end{array}$ & 471 & 94.2 \\
\hline & HEWs & 29 & 5.8 \\
\hline \multirow[t]{3}{*}{ ANC starting time } & at $<3$ month & 54 & 10.8 \\
\hline & at 3-4 month & 310 & 62.0 \\
\hline & $>/=5$ month & 136 & 27.2 \\
\hline \multirow[t]{3}{*}{ Plan of ANC visit } & $<4$ visits & 14 & 2.8 \\
\hline & 4 visits & 471 & 94.2 \\
\hline & $>4$ visits & 15 & 3.0 \\
\hline \multirow[t]{3}{*}{ Para } & 0 & 135 & 27.0 \\
\hline & $1-3$ & 227 & 45.4 \\
\hline & $>/=4$ & 138 & 27.6 \\
\hline
\end{tabular}

reported obstetric danger sign was considered, 484 (96.8\%) had it during pregnancy, 483 (96.6\%) at labor/ childbirth, and 455 (91\%) in the postpartum period.

\section{Knowledge of respondents about preparation for birth and its complications}

All of the respondents reported that they had information about BPCR. Out of the total respondents, 223 (44.6\%) were considered as knowledgeable. Regarding each recommended element which had to be done as BPCR; 440 (88\%) said they saved money for delivery and possible obstetric emergency, 429 (85.8\%) identified place of delivery, 109 (21.8) arranged potential blood donor, and 142 (28.4) spontaneously chose a skilled birth attendant (Table 3).

\section{Birth preparedness and complication readiness practices of respondents}

The majority of the respondents reported making arrangements for some of the recommended elements of BPCR. Out of 500 participants, 391 (78.2\%), 175 (35\%), 336 (67.2\%), 202 (40.4\%), and 104 (20.8\%) identified health facilities for delivery, skilled birth attendants, financial sources
Table 3 Knowledge of birth BPCR among pregnant women in Tehuledere district, northeast Ethiopia, 2015

\begin{tabular}{llll}
\hline Variable & Response & Frequency & Percentage \\
\hline Identification of health facility & No & 71 & 14.2 \\
& Yes & 429 & 85.8 \\
Identification of skilled birth & No & 358 & 71.6 \\
attendant & yes & 142 & 28.4 \\
Saving money & No & 60 & 12.0 \\
Preparation of transport & Yes & 440 & 88.0 \\
& No & 306 & 61.2 \\
Identification of temporary & Yes & 194 & 38.8 \\
family caregiver & No & 199 & 39.8 \\
Arranging blood donor & Yes & 301 & 60.2 \\
Identification of birth companion & No & 391 & 78.2 \\
& Yes & 109 & 21.8 \\
Identification of decision-maker in & No & 206 & 41.2 \\
case of emergency & Yes & 293 & 58.8 \\
Identification of medical facility in & No & 88 & 41.4 \\
case of emergency & Yes & 412 & 82.4 \\
Knowledge about BPCR & No & 277 & 55.4 \\
knowledgeable & Yes & 223 & 44.6 \\
\hline
\end{tabular}

for delivery and possible obstetric emergencies, modes of transport, and potential blood donors, respectively. Similarly, out of the same number of participants, 352 (70.4\%) identified a temporary family caregiver in case of emergency, 348 (69.6\%) chose a birth companion, 380 (76\%) selected medical facility in case of obstetric emergency, and 346 (69.2\%) nominated decision maker in case of obstetric emergency. Overall, $43.4 \%$ of the women practiced BPCR.

\section{Maternal socio-demographic and obstetric characteristics associated with their practices of birth preparedness and complication readiness}

In the bivariate logistic regression analysis, a statistically significant association $(p<0.05)$ was observed between maternal practices of BPCR and their educational status, gestational age, spouse occupation, knowledge of danger signs during pregnancy and childbirth, number of ANC visits, marital status, residence, spouse education, knowledge of BPCR, monthly income, and starting time of ANC service. In the multivariate logistic regression analysis, a statistically significant association was observed on knowledge of women on BPCR [AOR $=1.648$, 95\% CI: 1.073, 2.531]. Similarly, women knowledgeable about danger signs during pregnancy were three times more likely to practice BPCR compared to those who had no knowledge about danger signs during pregnancy [AOR 
$=2.802,95 \%$ CI: 1.637, 4.793]. Pregnant women with a gestational age of 4-6 months were three times more likely to practice BPCR than women whose gestational age was up to three months $[\mathrm{AOR}=3.379,95 \% \mathrm{CI}$ : $2.114,5.401]$. In addition, pregnant women who started ANC follow-up within 3-4 months of their pregnancy were three times more likely to practice BPCR compared to with those who started late $[\mathrm{AOR}=2.841,95 \%$ CI:1.330, 6.068] (Table 4).

\section{Discussion}

The aim of this study was to examine mainly the BPCR practice of pregnant women. Our study revealed that only less than half of the participants were practicing BPCR (217 or $43.4 \%$ ) and that a nearly equal number of women were knowledgeable about the practice (223 or 44.6\%).

The majority of the respondents reported that they made some arrangements on some of the recommended elements of BPCR. Out of five hundred respondents, 391 (78.2\%) identified a health facility for delivery, 175 (35\%) identified a skilled birth attendant, 336 (67.2\%) saved money for delivery and any possible obstetric emergency, 202 (40.4\%) determined mode of transport, $104(20.8 \%)$ identified potential blood donor in case of emergency, $352(70.4 \%)$ selected temporary family care giver, 348 (69.6\%) nominated birth companion, 380 (76\%) identified medical facility in case of obstetric emergency, and 346 (69.2\%) selected decision maker in case of obstetric emergency. Generally, only 217 (43.4\%) of the participants made BPCR arrangements.
In this study, $391(78.2 \%)$ pregnant women identified health facility for delivery. This is almost comparable with the findings of studies done in Jimma town and Goba woreda, Oromia Region, Ethiopia, which reported $285(81 \%)$ and $432(76.9 \%)$, respectively [18, 20]. However, the finding of this study is lower than that of a study done in Mpwapwa district Tanzania which detected 583 (97.3\%) [12]. The likely explanations for this dissimilarity might be differences in study subjects and settings. On the other hand, this finding is higher than those of studies done in Adigrat town, northern Ethiopia, and Aleta wondo, southern Ethiopia, which reported $209(39.1 \%)$ and $59(8.1 \%)$, respectively $[17,19]$. This difference might be due to variations in the times of investigations in that currently some more attention is being to the issue by maternal health implementers. Accessing health extension workers nearby in the community might increase the number of ANC attendants and improve decision on the identification of health facility for delivery.

The finding of the current study showed that 175 (35\%) of the respondents identified skilled birth attendants. This finding was lower than those of studies done in Indore City, India, which noted 217 (69.6\%), Mpwapwa district, Tanzania 436 (86.2\%), and Chamwino district, Tanzania $333(77.8 \%)$ [11, 12, 24]. The observed discrepancy might be due to study settings, target populations, and knowledge of women about BPCR and obstetric danger signs during pregnancy, labour, and postpartum period. Conversely, it was higher than the findings of studies conducted in Adigrat and Duguna Fango district, Wolayta

Table 4 Maternal socio-demographic and obstetric characteristics associated with BPCR practices in Tehuledere district, northeast Ethiopia, 2015

\begin{tabular}{|c|c|c|c|c|c|c|c|}
\hline \multirow[t]{2}{*}{ Variables } & & \multicolumn{3}{|c|}{ Practices of BPCR } & \multicolumn{2}{|c|}{ 95\% C.I. for AOR } & \multirow[t]{2}{*}{$P$-value } \\
\hline & & No & Yes & $\mathrm{AOR}$ & Lower & Upper & \\
\hline \multirow[t]{3}{*}{ Gestational age* } & up to 3 month & 133 & 52 & 1 & & & \\
\hline & at $4-6$ month & 132 & 158 & 3.379 & 2.114 & 5.401 & .000 \\
\hline & at 7-9 month & 18 & 7 & 1.422 & .512 & 3.948 & .500 \\
\hline \multirow[t]{2}{*}{ Residence $^{*}$} & Urban & 44 & 65 & 1 & & & \\
\hline & Rural & 239 & 152 & .442 & .244 & .803 & .007 \\
\hline \multirow[t]{3}{*}{ Starting time o $\mathrm{ANC}^{*}$} & at $<3$ month & 38 & 16 & 1 & & & \\
\hline & at 3-4 month & 166 & 144 & 2.841 & 1.330 & 6.068 & .007 \\
\hline & $>/=5$ month & 79 & 57 & 1.278 & .555 & 2.942 & .564 \\
\hline \multirow[t]{2}{*}{ Knowledge of BPCR* } & Not knowledgeable & 177 & 100 & 1 & & & \\
\hline & Knowledgeable & 106 & 117 & 1.648 & 1.073 & 2.531 & .023 \\
\hline \multirow{2}{*}{$\begin{array}{l}\text { Knowledge of danger signs } \\
\text { during pregnancy* }\end{array}$} & Not knowledgeable & 101 & 27 & 1 & & & \\
\hline & Knowledgeable & 182 & 190 & 2.802 & 1.637 & 4.793 & .000 \\
\hline \multirow[t]{3}{*}{ Partner occupation } & Farmer & 229 & 125 & 1 & & & \\
\hline & Employee & 12 & 52 & 2.259 & .891 & 5.723 & .086 \\
\hline & Merchant & 32 & 50 & 2.280 & 1.263 & 4.114 & .06 \\
\hline
\end{tabular}


Zone which reported 56 (10.5\%) and 62 (10.9\%), respectively $[17,25]$. The difference could be due to the study period, an increased number of ANC visits which might have increased access to information. The expansion of Health Extension Workers (HEWs) to the rural community might have created an opportunity for raising women's knowledge regarding the role of skilled attendants at birth.

In the present study, saving money for delivery and any possible obstetric emergency was 336 (67.2\%). This result was consistent with 388 (69\%) of a study conducted in Goba woreda, Oromia Region [18]. However, our finding was lower than those of studies conducted in Indore City, India, Chamwino district, Tanzania, West Bengal, India, Mpwapwa district, Tanzania, and in Plateau State, Nigeria which reported 240 (76.9\%), 360 (84.1\%), 84.6\%, 536 (89.3\%), and 209 (83.6\%), respectively $[11-13,24,26]$. This could be due to differences in settings, resulting in variations in socio-economic status, culture, and level of female empowerment. If women are empowered educationally and economically, they could have a better understanding of obstetric danger signs or complications and benefit from BPCR and save money for delivery and obstetric complication services. However, the current finding was higher than those of studies conducted in Duguna Fango district, Wolayta Zone 308 (54.1\%) and Adigrat 190 (35.6\%) [27, 17]. The difference might be due to variations in the study period and knowledge status of women about BPCR. The knowledge level of the respondents about BPCR was higher compared to the above studies. This fact showed that women who knew that money could help them to buy important medical supplies or pay for transportation in case of delivery and obstetrics emergency made better BPCR arrangements.

This study revealed that $202(40.4 \%)$ of the pregnant women arranged the mode of transportation for delivery/obstetric emergency. This finding corroborated a study conducted in Adigrat and noted 40.8\% [17]. However, the finding was lower compared with those of studies conducted in Mpwapwa district, Tanzania and Plateau State, Nigeria which reported $494(82.3 \%)$ and 135 (54\%), respectively [12, 13]. This could be because of variations in study settings, resulting in differences in socio-economic status and access to transportation. But our finding was higher than the result of a study (103/ 18.1\%) done in Fango district, Wolayta Zone [27]. This could be due to an increase in the number of HEWs and repeated ANC visits which might have created awareness on the benefits of early arrangement for transportation. In cases of geographical inaccessibility or financial problems, our community arranged traditional ways of transportation such as donkeys, horses, or mules and local stretchers. Identifying transportation ahead of childbirth and improvement in decision-making can reduce maternal and neonatal mortality.

Our study found that $104(20.8 \%)$ of the women identified potential blood donors in cases of emergency. This finding was similar to that of a study done in Plateau State, Nigeria which reported 58 (23.2\%) [13]. But it was higher than the results of studies done in Fango district, Wolayta Zone 17 (3.0\%), Goba woreda, Oromia Region 51 (9.1\%), Robe woreda, Arsi Zone 57 (9.9\%) and Adigrat $4(0.7 \%)[17,18,21,27]$. This might be due to an improvement in the knowledge of pregnant women and their families about the importance of early identification of blood donors. In this study, nearly $100 \%$ of the pregnant women attended ANC which created a good opportunity for getting appropriate information on the elements of BPCR by skilled birth attendants. Making arrangements for blood donors is important because women giving birth may need a blood transfusion in the event of hemorrhage or cesarean section.

This study indicated that $352(70.4 \%)$ of the pregnant women identified temporary family caregivers. This finding was lower than that of a study done in Mpwapwa district, Tanzania and documented 548 (91.3\%) [12]. This could be due to differences in study settings resulting in variations in the quality of counseling and strength of applying BPCR strategy in order to reduce maternal and child mortality.

In the current study, 380 (76\%) of the women identified the medical facility in preparation for the obstetric emergency. The result of this study was higher than the result of a study done in Fango district, Wolayta Zone, Goba woreda, Oromia Region, and Adigrat town, northern Ethiopia, which found out $43.6 \%, 47.5 \%$ and $6.6 \%$, respectively $[17,18,27]$. This could be due to the expansion of the Health Extension Program which might have improved the number of ANC attendants in the health facilities- which probably increased awareness on obstetric danger signs and arrangements for medical facilities to cope with obstetric emergencies.

The finding showed that 346 (69.2\%) of the respondents identified decision makers for cases of obstetric emergency. This finding is lower than that of a study conducted in Mpwapwa district, Tanzania, and noted $564(94.0 \%)$ [12]. This difference might be due to variations in the socio-economic and educational status of women and the implementation of BPCR strategies. But the finding was higher than $12(2.2 \%)$ reported from Adigrat, northern Ethiopia [17]. This could be due to differences in study periods. That is, currently the Ethiopian government has given special attention to BPCR integration and implementation at the grassroot levels by each primary health care unit and the emphasis given to male involvement in maternal health care services which might have encouraged 
women to identify decision-makers in cases of obstetric emergencies.

In this study, 217 (43.4\%) respondents practiced BPCR. The finding was lower than the results of studies done in Indore City, India, Chamwino district, central Tanzania, Edo State, Nigeria, and the rural area of Darjeeling West Bengal, India, which reported (47.8\%), (58.2\%), (87.4\%), and (57\%), respectively [11, 24-26]. The possible reason could be the differences in study areas as the current study included both rural and urban/city communities. However, it was higher than those of studies done in rural Uganda, Aleta Wondo, southern Ethiopia, Adigrat town, northern Ethiopia, Jimma town southwest Ethiopia, Goba woreda, Oromia Region, Ethiopia, Robe woreda, Arsi zone, Oromia Region, central Ethiopia, and Dugna Fango district, Wolayta Zone, Ethiopia, which found (35\%), (17\%), (22.1\%), (29.4\%), (29.9\%), (18.3\%), and (16.5\%), respectively $[15,17-21,27]$. The likely reason for the difference could be that the recommended BPCR elements might have been given more focus in these healthcare setups.

In the multivariate logistic regression analysis, knowledge of BPCR was two times more likely to encourage BPCR practice compared to no knowledge. This finding is inconsistent with that of a study done in Goba woreda [18]. The possible reason for the difference could be the quality of information given to women about BPCR. Increasing the number of ANC attendants and knowledge on the elements of BPCR to pregnant women during each visit might motivate them to prepare for birth and to be ready for obstetric complications.

Participants knowledgeable about danger signs during pregnancy were three times more likely to practice BPCR compared to those who had no knowledge. This finding is similar to those of studies done in Goba and Robe woredas, Ethiopia, but differs from that of a study done in Adigrat [17, 18, 21]. The possible reason could be the study period and the clarity of information on BPCR addressed at times of repeated ANC visits. Besides, their partners might have been involved in BPCR. Knowledge about the danger signs of obstetric complications is important for recognizing complications early and taking immediate actions to access essential emergency obstetric care.

Pregnant women who started their ANC services within three to four months of pregnancy were three times more likely to be prepared to practice BPCR compared with those who started late. This finding was in line with those of studies conducted in Robe woreda, Arsi Zone, Fango district, Wolayta Zone and Goba woreda [18, 21, 27]. This might indicate that there was a better exposure to information on BPCR during the repeated visits.

Rural pregnant women were 0.44 times less likely to be prepared for BPCR. That is, urban dwellers were more likely to be prepared for BPCR. This finding is similar to that of a study done in Goba woreda [18]. The possible reason could be that urban residence improves access to information, service, and BPCR practice.

Limitations of this study were since the design of our work was cross-sectional; it might not have been strong enough to demonstrate the cause and effect relationships between dependent and independent variables. In addition, as the data collectors were health professionals, there was a possibility of social desirability bias in the responses to some of the variables.

\section{Conclusion}

The present study identified that there has been poor preparedness for birth and complications. Residence, knowledge about BPCR and danger signs during pregnancy, gestational age, and the starting time of ANC service were significantly associated with BPCR practice.

Health professionals should create awareness on birth preparedness and complication readiness among pregnant mothers, families, or communities. Government officials, partners, and health care providers that are working in areas of maternal and child health should work together to ameliorate factors that influence the low practice of birth preparedness and complication readiness. Researchers need to conduct qualitative studies to explore the main reasons for their poor preparedness of pregnant women for birth and in cases of obstetric complications in order to bring significant changes in the reduction of maternal and neonatal deaths.

\section{Additional files}

Additional file 1: English version questionnaire. (DOCX $28 \mathrm{~kb}$ ) Additional file 2: Amharic version questionnaire. (DOCX $30 \mathrm{~kb}$ )

\begin{abstract}
Abbreviations
ANC: Antenatal care; BPCR: Birth preparedness and complication readiness; BSc: Bachelor of science; EDHS: Ethiopian demographic health survey; EFMOH: Ethiopian federal ministry of health; ETB: Ethiopian birr; FMOH: Federal ministry of health; HAD: Health development army; HEWs: Health extension workers; MDGs: Millennium development goals; MMR: Maternal mortality ratio; NGOs: Non-governmental organizations; PNC: Postnatal care; SNNP: Southern nations, nationalities, and people; SPSS: Statistical package for social sciences; TBA: Traditional birth attendant: WHO: World Health Organization
\end{abstract}

\section{Acknowledgements}

The authors would like to acknowledge the data collectors and the supervisor for their unreserved work. They also forwarded compliments to the study participants for providing the necessary information.

\section{Funding}

The funding body was the University of Gondar for data collection and analysis. However, the funder has no role in manuscript preparation and publication. 


\section{Availability of data and materials}

"The datasets used and/or analyzed during the current study will be available from the corresponding author upon reasonable request".

\section{Authors' contributions}

DB wrote the proposal, implemented the proposal, analyzed the data and drafted the paper. HY participated in revising the proposal and involve on data analysis and the subsequent drafts of the paper. LD worked on the methodology and analysis sections of the study, as well as the discussion section. All authors read and approved the final manuscript.

\section{Authors' information}

Principal Investigator: Demlie Belete Endeshaw.

\section{Ethics approval and consent to participate}

Ethical approval was obtained from University of Gondar, College of Medicine and Health Science, Institute of Public Health Institutional Review Board (IRB). Letter of permission to conduct the study at the area was collected from Tehulederie Woreda Health Office. Since the authors thought that there was no any potential risk associated on the provision of the data and it is a cross-sectional study, informed verbal consent was considered and obtained from each respondent. The ethics committee also approved the appropriateness of the informed verbal consent for this study. Participants were informed about their rights to decline if they didn't want to continue. The questions were coded instead of using names; so confidentiality was assured throughout the study. Involving the use of any animal or human data or tissue: "Not applicable" in this research section. Data from any individual person in any form (including individual details, images or videos): "Not applicable" in this research.

\section{Consent for publication}

"is not applicable" in the cross-sectional study.

\section{Competing interests}

The authors declare that they have no competing interests.

\section{Publisher's Note}

Springer Nature remains neutral with regard to jurisdictional claims in published maps and institutional affiliations.

\section{Author details}

'Maternal and Child Survival Program (MCSP), Community Based Newborn Care (CBNC) Coordinator, Save the children, Woldia, Ethiopia. ${ }^{2}$ Department of Epidemiology and Biostatistics, Institute of Public health, University of Gondar, Gondar, Ethiopia. ${ }^{3}$ Department of Reproductive Health, Institute of Public health, University of Gondar, Gondar, Ethiopia.

\section{Received: 5 April 2017 Accepted: 27 February 2018}

\section{Published online: 15 March 2018}

\section{References}

1. World Health Organization (WHO). Preventing maternal deaths. 1989.

2. Luwei $P$, Margareta $L$, Vincent F, Judith S. Childbirth care, opportunities for African newborns. 2012.

3. Family Care International London. Women deliver organization partner. 2007.

4. JHPIEGO. Monitoring birth preparedness and complication readiness, tools and indicators for maternal and newborn health. 2004.

5. The White Ribbon Alliance for Safe Motherhood. Saving mothers' lives. India; 2010,

6. Kakaire O, Kaye DK, Osinde MO. Male involvement in birth preparedness and complication readiness for emergency obstetric referrals in rural Uganda. Reprod Health. 2011;8:12.

7. Thaddeus S, Maine D. Too far to walk maternal mortality in context. Soc Sci Med. 1994;38(8):1091-110.

8. Program J-ManhM. Birth preparedness and complication readiness: a matrix of shared responsibilities. 2001.

9. Ethiopia Press materials. No woman should die while giving life, safe motherhood monthly calls for zero home deliveries. 2014.

10. Central Statistical Agency Addis Ababa Ethiopia. Ethiopian mini demography and health survey. 2014.
11. Agarwal S, Sethi V, Srivastava K, Jha PK, Baqui AH. Birth preparedness and complication readiness among slum women, Indore City, India. International center for diarrheal disease research, Bangladesh. J Health Popul Nutr. 2010;28(4):383-91.

12. Urassa DP, Pembe AB, Mganga F. Birth preparedness and complication readiness among women in Mpwapwa district, Tanzania. Tanzania J Health Res. 2012;14(1):42-7.

13. Envuladu EA, Zoakah Al. Assessment of the birth and emergency preparedness level of pregnant women in Jos, plateau state. Nigeria IJBAIR. 2014;3(1):2-7.

14. Kuganab-Lem RB, Dogudugu R, Kanton L. Birth preparedness and complication readiness: a study of postpartum women in a rural district of Ghana. Public Health Research. 2014;4(6):225-33. https://doi.org/10.5923/j. phr.20140406.02.

15. Kabakyenga JK, Östergren P-O, Turyakira E, Pettersson KO. Knowledge of obstetric danger signs and birth preparedness practices among women in rural Uganda. Reprod Health. 2011;8:33.

16. Kuteyi EAA, Kuku JO, Lateef IC, Ogundipe JA, Mogbeyteren T, Banjo MA. Birth preparedness and complication readiness of pregnant women attending the three levels of health facilities in Ife central local government, Nigeria. J Community Med \& Prim Health. 2011;23(1-2).

17. Hiluf $M$, Fantahun $M$. Birth preparedness and complication readiness among women in Adigrat town, northern Ethiopia. EthiopJHealth Dev. 2007;22(1):14-20.

18. Markos D, Bogale D. Birth preparedness and complication readiness among women of childbearing age group, Goba woreda, Oromia region. Ethiopia BMC Pregnancy and Childbirth. 2014;14:282.

19. Hailu M, Gebremariam A, Alemseged F, Deribe K. Birth preparedness and complication readiness among pregnant women, Aleta Wondo, southern Ethiopia. PLoS One. 2011;6(6):e21432. https://doi.org/10.1371/journal.pone. 0021432.

20. Kitila SB, Tebeje B. Predictors of birth preparedness and complication readiness among pregnant women in Jimma town, Southwest Ethiopia. Research. 2014;1:595.

21. Kaso M, Addisse M. Birth preparedness and complication readiness in robe district, Arsi zone, Oromia region, Central Ethiopia. Reprod Health. 2014;11:55.

22. Central Statistics Agency Ethiopia. Census report. 2007.

23. South Wollo Zone Health Department Dessie Ethiopia. Annual key indicators performance report by Woreda. 2013/2014.

24. Bintabara D, Mohamed MA, Mghamba J, Wasswa P, Mpembeni RNM. Birth preparedness and complication readiness among recently delivered women in Chamwino district, Central Tanzania. Reprod Health. 2015;12:44. https:// doi.org/10.1186/s12978-015-0041-8.

25. Tobin EA, Ofili AN, Enebeli N, Enueze O. Assessment of birth preparedness and complication readiness among pregnant women attending at primary health care Centres in Edo state. Nigeria Annals of Nigerian Medicine. 2014;8(2):76-81.

26. Mandal T, Biswas R, Bhattacharyya S, Das DK. Birth preparedness and complication readiness among recently delivered women in a rural area of Darjeeling, West Bengal. India AMSRJ. 2015;2(1):14-20.

27. Gebre M, Gebremariam A, Abebe TA. Birth preparedness and complication readiness among pregnant women in Duguna Fango district, Wolayta zone. Ethiopia PLoS ONE. 2015;10(9):e0137570. https://doi.org/10.1371/journal. pone.0137570.

\section{Submit your next manuscript to BioMed Central and we will help you at every step:}

- We accept pre-submission inquiries

- Our selector tool helps you to find the most relevant journal

- We provide round the clock customer support

- Convenient online submission

- Thorough peer review

- Inclusion in PubMed and all major indexing services

- Maximum visibility for your research

Submit your manuscript at www.biomedcentral.com/submit
C Biomed Central 